\title{
Mixed methods, crimes, and misdemeanours
}

\author{
Rachel Ellaway ${ }^{1}$
}

(c) Springer Nature B.V. 2020

Editorials can try to do many things: reflect on the state of the science, suggest ways of thinking about emerging issues, or just talk about the business of the Journal in general. And sometimes they can seek to address a problem in the material being submitted to the Journal; this is one of those editorials. In this issue, I am writing this as a plea to those submitting their papers to this Journal and as a direction to scientists in our field more broadly to be more thoughtful and grounded in the use of mixed methods research (MMR).

Over the years, I have seen many papers submitted to AHSE claiming to be mixed methods research (MMR) but few that have situated themselves robustly within the discourses of MMR. This is despite the applied and pragmatic tendencies of much of the scholarly work undertaken in health professions education research often mapping well to MMR approaches. After all, even at the most simplistic level, adding a 'what' dimension to a 'why' study or vice versa can make all the difference in substantiating a study's knowledge claims. So, my concern is that, while MMR seems, based on submissions to AHSE and its appearance elsewhere, to be of growing interest and utility in health professions education research, the sophistication has all too often been lacking in the design, execution, and reporting of these studies. I therefore offer the following in thinking about and engaging in MMR.

Firstly, MMR is not simply a conjunction of methodologies or paradigms; it is a paradigm in and of itself with a robust and dynamic methodological basis. This is reflected in its publications, such as The Journal of Mixed Methods Research, which provide a lively discourse about the use of MMR. See, for instance, the paper from Johnson et al. (2007) reflecting on the many conceptualizations of MMR. Naturally, these debates have also been pursued in other venues. See for instance Shaw et al. on how MM researchers need to consider: the paradigms they draw on, the logic of combining them, the specific nature of the different methods employed, the analytical strategy (theory-driven, data driven, or explanation driven), and critical evaluation of the knowledge claims made (their validity, reliability and objectivity, credibility, transferability, trustworthiness, and confirmability). See also Yanchar and Williams (2006) who called for researchers to always consider five factors in selecting any method or methods: contextual sensitivity, creativity, conceptual awareness, coherence, and critical reflection. If a single reference manual is needed, then the Tashakkori and Teddlie source provides an excellent collection of articles (2010).

Rachel Ellaway

rachel.ellaway@ucalgary.ca

1 Cumming School of Medicine, University of Calgary, Calgary, AB, Canada 
Those engaging in MMR should be able to situate their work within its debates, just as they would for any other methodological paradigm. However, what I often see instead is a single citation, typically a student-focused research primer, as the only methodological source. While there are many excellent textbooks for helping students to develop their research skills (I regularly use these texts in my own teaching), they summarize their primary sources (as all textbooks do) in order to create a simplified instructional narrative. If a biomedical research team's sole methodological reference for their work was their undergraduate textbook then they would scarcely be considered credible, at least in a theory and methods-focused journal. And so, I would argue, it is with MMR.

The dominant presence of the Creswell and Plano Clark textbook (2017) in particular has lent their topological typology of MMR designs (sequential, parallel etc.) a degree of authority that has tended to downplay other facets of MMR inquiry. The sequencing of different methods and the reasons for that sequencing is an important part of the design but it is not the only or even the most important aspect of the design (Sandelowski et al. 2012). Moreover, MMR is not just a matter of using different methods together-in practice quite what is mixed and what is not mixed is often more nuanced. As an illustration, Cook (1985) focused on the many different ways in which multiples ('multiplism') might be used in social research, noting that designs might: measure concepts in different ways, measure different constructs. use multiple data collection methods, use multiple interconnected studies, synthesize multiple studies, construct multivariate causal models, competitively test rival models and hypotheses, engage multiple stakeholders, employ multiple theoretical and value frameworks, use multiple analytical techniques and analysts; and/or pursue multiple different questions and issues. MMR can involve many layers and dimensions of mixing, which in any given study may or may not be employed to differing degrees.

Another commonly made assertion that I would challenge is that MMR must involve one qualitative method plus one quantitative method. To me it seems self-evident that any combination of different methods (wherever they sit on a qual-quan, or any other continuum) is by definition MMR. It must be more than one, but it can certainly be more than two, and, given the pragmatic use of techniques from different methodologies (Kennedy and Lingard 2006), it doesn't have to be limited to an integer either. Mixing can involve flavours and ingredients from different methods and methodologies, not just the collisions between unitary methodological monoliths.

Paradigm mixing also raises issues regarding the compatibility of their differing underlying assumptions and constructs. As an example, Greene described different stances for paradigm mixing in MMR (2007): a purist stance (methods must share a common mental model to be combinable) an a-paradigmatic stance (practical needs are more important than philosophical inconsistencies); a substantive theory stance (theory is more important than method); a complementary strengths stance (different paradigms yield important different perspectives); a dialectical stance (juxtapositions of methods afford new insights); and an alternative paradigms stance (pragmatic, realist, and emancipatory approaches to inquiry). Greene also noted a number of different inferential logics for MMR: triangulation (results from one method confirm those from another); complementarity (results from different methods add breadth and depth); development (results from method inform the use of others); initiation (different methods offer usefully conflicting views); and expansion (different methods are used for exploring different constructs or phenomena). These logics of inquiry (Shaw et al. 2018) are critical in establishing the veracity and reliability of any inferences made from an MMR study and yet they are rarely clearly articulated or situated in the MM research I see in our field. 
The broader point I want to make is that there are many facets that need to be considered in engaging in MMR that can, when used well, add depth and substance to acts of inquiry and the knowledge claims they generate. Not paying attention to the factors that define the MMR paradigm will render studies anaemic and suspect, no matter their other merits. And this means that those looking to engage in MMR and those who want to better understand the intersectionality of the paradigms at play in health professions education need to ground their understanding and their work in the concepts and debates that define this aggregative paradigm. It means being clear about and justifying what it is that researchers are mixing, what they are not mixing, and why they are doing what they are doing. It means making explicit what the mixed design is supposed to achieve, the bases and limitations for any inferences generated from this design, and how these decisions and the study design they generate relate to the MMR literature. An applied field, such as health professions education, has much to gain from using mixed methods. I ask therefore that, if you are going to mix things up, then you do it in transparent, well-grounded, and rigorous ways.

\section{AHSE anniversary issue}

Our next issue of Advances, the final one in 2020, is our 25th anniversary issue celebrating the 25 years that Dr. Geoff Norman served as Editor in Chief (and founding editor) of the Journal. We will be presenting a range of commissioned and prospective papers on a range of topics looking back on and looking forward to the development of the field and the sciences we pursue within it. We are looking forward to this milestone in the Journal's development and all that is to follow.

\section{References}

Cook, T. D. (1985). Post-positivist critical multiplism. In R. L. Shortland \& M. M. Mark (Eds.), Social science and social policy (pp. 21-62). Thousand Oaks, CA: Sage.

Creswell, J. W., \& Plano Clark, V. L. (2017). Designing and conducting mixed methods Research (3rd ed.). Thousand Oaks, CA: Sage.

Greene, J. C. (2007). Mixed methods in social inquiry. San Francisco, CA: Jossey-Bass.

Johnson, R. B., Onwuegbuzie, A. J., \& Turner, L. A. (2007). Toward a definition of mixed methods research. Journal of Mixed Methods Research, 1(2), 112-133.

Kennedy, T. J., \& Lingard, L. A. (2006). Making sense of grounded theory in medical education. Medical Education., 40(2), 101-108.

Sandelowski, M., Voils, C. I., Leeman, J., \& Crandell, J. L. (2012). Mapping the mixed methods-mixed research synthesis terrain. Journal of Mixed Methods Research, 6(4), 317-331.

Shaw, R. L., Hiles, D. R., West, K., Holland, C., \& Gwyther, H. (2018). From mixing methods to the logic(s) of inquiry: Taking a fresh look at developing mixed design studies. Health Psychology and Behavioral Medicine, 6(1), 226-244.

Tashakkori, A., \& Teddlie, C. (2010). SAGE handbook of mixed methods in social \& behavioral research (2nd ed.). Thousand Oaks, CA: Sage.

Yanchar, S. C., \& Williams, D. D. (2006). Reconsidering the compatibility thesis and eclecticism: Five proposed guidelines for method use. Educational Researcher, 35(9), 3-12.

Publisher's Note Springer Nature remains neutral with regard to jurisdictional claims in published maps and institutional affiliations. 